\title{
An increase in primary care prescriptions of stop-smoking medication as a result of health insurance coverage in the Netherlands: population based study
}

\author{
Marjolein E. A. Verbiest', Niels H. Chavannes', Mathilde R. Crone', Mark M. J. Nielen², \\ Dewi Segaar ${ }^{3}$, Joke C. Korevaar ${ }^{2}$ \& Willem J. J. Assendelft ${ }^{1,4}$
}

Leiden University Medical Centre, Department of Public Health and Primary Care, Leiden, the Netherlands,' Netherlands Institute for Health Services Research, Utrecht, the Netherlands, ${ }^{2}$ STIVORO, Dutch Expert Centre on Tobacco Control, the Hague, the Netherlands ${ }^{3}$ and Radboud University Nijmegen Medical Centre, Department of Primary and Community Care, Nijmegen, the Netherlands ${ }^{4}$

\begin{abstract}
Aims To examine the impact of two national tobacco control interventions in the past decade on (dispensed) prescriptions of stop-smoking medication. Design Ecological study with interrupted time-series analyses of quarterly data points of three nation-wide representative databases. Setting The Netherlands 2001-2012, with the introduction of the guideline for smoking cessation care for general practitioners (GP) in 2007 and full insurance coverage for smoking cessation treatment in 2011. Participants GPs, pharmacists and people in the general population aged 15 years and older. Measurements Time-series plots were inspected visually and segmented regression analyses were performed to estimate the change in level and slope of (dispensed) prescriptions of stop-smoking medication and smoking prevalence in the years preceding and after the tobacco control interventions. Findings No measurable effects of the GP guideline on (dispensed) prescriptions were observed. Shortly after the start of health insurance coverage, an estimated increase in primary care prescriptions of 6.3 per 1000 smokers [95\% confidence interval $(\mathrm{CI})=2.9-9.8 ; P=0.001]$ and 17.3 dispensed items per 1000 smokers $(95 \% \mathrm{CI}=12.5-22.0 ; P<0.000)$ was accompanied by a sudden drop in smoking prevalence of $2.9 \%(95 \% \mathrm{CI}=4.6-1.1 ; P=0.002)$ in the first quarter of 2011. Immediately after the coverage abolition, smoking prevalence increased by $1.2 \%(95 \% \mathrm{CI}=0.5-2.8 ; P=0.156)$ and dispensed prescription rates decreased with 21.6 per 1000 smokers $(95 \% \mathrm{CI}=26.0-17.2 ; P<0.000)$. Conclusions Full health insurance coverage for smoking cessation treatment in the Netherlands was accompanied by a significant increase in the number of (dispensed) prescriptions of stop-smoking medication and a decrease in smoking prevalence.
\end{abstract}

Keywords Drug prescriptions, health policy, primary health care, smoking cessation, tobacco use cessation products.

Correspondence to: Marjolein E. A. Verbiest, Leiden University Medical Centre, Department Public Health and Primary Care, PO Box 9600,2300 RC Leiden, the Netherlands. E-mail: m.e.a.verbiest@lumc.nl

Submitted 19 December 2012; initial review completed 7 February 2013; final version accepted 25 June 2013

\section{INTRODUCTION}

In the past decade, cigarette consumption has declined in various high- and middle-income countries [1]. However, about $25 \%$ of the Dutch adult population still smokes [2]. As a result, in the Netherlands, the attributive risk of smoking-related mortality is estimated at $21 \%$, which is relatively high compared to $16 \%$ in Europe and 12\% world-wide [3,4]. Consequently, $13 \%$ of the Dutch disease burden and an annual $€ 2$ billion in health-care costs are attributed to the use of tobacco $[4,5]$.

Therefore, in the last decade multiple national tobacco control interventions have been implemented [6,7]. The Dutch government initiated several policies aimed at reducing exposure to environmental tobacco smoke and discouraging tobacco use. Bans on tobacco 
advertisement (November 2002) and the sale of tobacco to minors (January 2003) were implemented, and legislation was introduced for smoke-free work-places (January 2004) and public places (April 2006 and July 2008). In addition, national guidelines for smoking cessation support in health care were developed and implemented. Moreover, in the year 2011, full health insurance coverage for evidence-based pharmacotherapy in combination with behavioural counselling was implemented.

These tobacco control interventions are likely to reduce smoking initiation, increase the number of quit attempts and/or use of effective treatments and therefore reduce smoking prevalence [8-15]. For example, in the Netherlands, smoking prevalence decreased from 30.1\% in 2001 to $25.9 \%$ in 2012 [2]. However, the impact of national tobacco control interventions on primary care prescriptions of stop-smoking medication is not yet clear.

GPs are more likely to deliver successful smoking cessation treatment when they use a systematic approach and when structural barriers (e.g. lack of financial reimbursement) are alleviated [16,17]. Therefore, we examined the impact of two national tobacco control interventions on prescriptions of stop-smoking medication in general practice that were likely to have directly prompted GPs to support smokers to quit. These two interventions are the guideline for smoking cessation care introduced in general practice and the full health insurance coverage period of stop-smoking treatment.

\section{METHODS}

\section{Design}

To explore the hypotheses, we used an ecological study design in which the unit of analysis was the population rather than the individual. The main advantage of this type of study is the presence of available data which enabled a relatively fast and inexpensive study. However, the results cannot be extrapolated to the individual level and no confounder data were available. Moreover, inferences regarding causality need to be made with caution, taking into account other explanations for changes in outcomes. Nevertheless, this type of study is useful to generate new hypotheses based on the results.

\section{National tobacco control interventions}

We assessed the impact of potentially high-impact national tobacco control interventions on prescriptions of stop-smoking medication in general practice, i.e. (i) the introduction of the GP guideline for smoking cessation care and (ii) full health insurance coverage of evidencebased pharmaceuticals and behavioural treatment for smoking cessation.
Implementation of the first Dutch guideline 'Treatment of Tobacco Dependence' started in 2004, accompanied by campaigns in which physicians and other health-care providers were informed about the guideline and were provided with additional insight into the addictive character of smoking [18]. This implementation period resulted in the first version of a guideline for treatment of tobacco use in general practice, developed by the Dutch College of General Practitioners in June 2007 [19]. This guideline recommends enquiring actively about a patient's motivation for stopping smoking. When a patient smokes more than 10 cigarettes/day and is motivated to quit, the first choice recommendation is to prescribe nicotine replacement therapy (NRT) in combination with behavioural treatment. If requested specifically by the patient, or in the case of relapse after NRT, the antidepressant smoking cessation agents bupropion and nortriptyline are recommended. In December 2006 varenicline was introduced in the Netherlands and (after an evaluation period) was incorporated into the general practitioner (GP) guideline in March 2011 [20].

In January 2011, the Dutch government introduced full health insurance coverage for evidence-based smoking cessation programmes using pharmacotherapy in combination with behavioural counselling. Governmental changes, a shift of focus of the Ministry of Health on people's autonomy regarding life-style choices, and overall cutting in budget, led to the cancellation of full health insurance coverage after only 1 year. As a result, only behavioural support and not pharmacological support for smoking cessation was reimbursed during the year 2012 .

We analysed the effects of both policies within the same regression model, which allowed us to quantify the effects of one policy taking into account the effect of the other policy.

\section{Data extraction}

For a full overview of the number of primary care prescriptions of stop-smoking pharmaceuticals in the past decade we used two nation-wide representative databases of (i) prescribed medication in general practice and (ii) prescriptions dispensed in out-patient pharmacies. The term 'prescription' refers to an order of the GP for the pharmacist to dispense and the patient to take the medication. The act of dispensing is defined as providing a patient with their labelled medication. In the Netherlands all stop-smoking medications are prescription drugs, with the exception of NRT, which is also available over the counter.

At quarterly intervals, we extracted data on prescriptions and dispensed items of stop-smoking medication in general practices and pharmacies. Data on nortriptyline 
were excluded because this pharmaceutical is also used for various other indications. Finally, to explore the impact of the tobacco control interventions on smoking prevalence a third database was used (see Data on smoking prevalence below).

The privacy regulation of the study was registered at the Dutch Data Protection Authority. According to current Dutch legislation, neither informed consent nor approval is required from a medical ethics committee for observational studies using anonymized data records [21].

\section{Data on stop-smoking medication prescribed in primary care}

The number of quarterly prescribed stop-smoking medications in general practice were derived from the Netherlands Information Network of Primary Care (LINH) in the period 2001-2011. Data were retrieved from electronic medical patient records, kept in a representative sample of 84 general practices with approximately 350000 listed patients. The characteristics of the study population (GPs and patients) are comparable with the general Dutch population in terms of age and gender [22]. We selected prescriptions of NRT, varenicline and bupropion in the period 2001-2011 and calculated prescription rates per 1000 smokers. These rates were calculated by dividing the absolute number of primary care prescriptions by the number of smokers, multiplied by 1000. The number of smokers was based on the total population [23] and smoking prevalence [24]. In this database it was not possible to differentiate between prescriptions of bupropion as an anti-depressant or for smoking cessation.

Data on stop-smoking medication dispensed by pharmacies

For prescriptions of stop-smoking medication dispensed in out-patient pharmacies, we used quarterly data of the Dutch Foundation for Pharmaceutical Statistics (SFK) in the period 2001-2012. The SFK gathers data from a representative panel of $95 \%$ of Dutch community pharmacies. Data were extrapolated to nation-wide figures. We selected dispensations of NRT, varenicline and bupropion in the period 2001-2012 and calculated dispensed rates per 1000 smokers.

\section{Data on smoking prevalence}

We used quarterly data from the Dutch Continuous Survey of Smoking Habits (DCSSH) from 2001 to 2012 for smoking prevalence. The DCSSH assesses smoking behaviour of the Dutch adult population (15 years and older). The DCSSH has been part of the CASI omnibus (Computer-Assisted Self-Interviewing) of TNS NIPO from 2001 to 2008. From 2009 onwards, the DCSSH has been performing an ad-hoc internet survey in which a representative sample of about 350 subjects is selected from a database of 200000 respondents every week. Until 2008, the data from the DCSSH were weighted on the basis of respondents' gender, age and education level, the province in which they lived and their family and community size. Since January 2009, the data have also been weighted on the basis of respondents' socio-economic status. Smoking prevalence was assessed by asking participants 'Do you (ever) smoke?'.

\section{Statistical methods}

We drew and visually inspected time-series plots to detect marked changes in the number of (dispensed) prescriptions and smoking prevalence in the past decade. Interrupted time-series analyses (SPSS version 20.0) were used to evaluate the impact of the national tobacco control interventions on (dispensed) prescriptions of stop-smoking medications and smoking prevalence [25]. The advantages of these analyses are the fact that they allowed us to assess whether or not the interventions changed the outcomes immediately as well as over a period of time, taking into account pre-existing trends in the data [25-27]. Prior studies have shown that segmented regression analysis is a suitable method for analysing interrupted time-series data in order to assess the impact of extraneous events on smoking-related outcomes [25,28-31]. We examined the following linear regression equation:

$$
\begin{aligned}
& Y_{t}=B_{0}+B_{1} \times \text { time }_{t}+B_{2} \times \text { intervention }_{t}+B_{3} \\
& \times \text { time after intervention } 1_{t}+B_{4} \times \text { intervention } 2_{t} \\
& +\mathrm{B}_{5} \times \text { intervention } 3_{t}+\mathrm{e}_{t}
\end{aligned}
$$

Time (in quarters) was included as a continuous predictor. Intervention indicated the introduction of the GP guideline, and the introduction and abolition of health insurance coverage of stop-smoking treatment; pre-intervention time-points were coded 0 and postintervention time-points were coded 1 . Time after intervention was coded 0 up to the last time-point before the intervention, and was coded sequentially from 1 thereafter.

In the model, $Y_{t}$ represents the outcome variable at time $t$ (the number of (dispensed) prescriptions per 1000 smokers or smoking prevalence). $B_{0}$ estimates the baseline level/intercept of the outcome at time-point zero; $B_{1}$ estimates the quarterly change in outcome prior to the interventions; $B_{2}$ (introduction GP-guideline), $B_{4}$ (introduction insurance coverage) and $B_{5}$ (abolition insurance coverage) estimates the change in level immediately after the interventions; and $B_{3}$ estimates the change in slope after the introduction of the GP-guideline compared with the slope before the intervention. We assessed both full 
and parsimonious models into which we incorporated all parameters regardless of their significance and only significant covariates, respectively.

We did not assess the impact of the GP guideline introduction on the number of (dispensed) prescriptions of varenicline because this pharmaceutical was introduced in the Netherlands around the same time as the GP guideline (December 2006). Furthermore, we only assessed the immediate effect of the introduction and abolition of the insurance coverage in (dispensed) prescriptions and smoking prevalence, as we lacked sufficient time-points to estimate a change in trend.

Because time is a predictor in segmented regression analyses it is likely that consecutive observations are correlated (called 'autocorrelation'). As regression analysis assumes independence between observation and autocorrelation can over- or underestimate significance, we examined autocorrelation by visually inspecting residual plots. Autocorrelation was judged to be present if there were statistically significant spikes in the correlogram. In addition, the Durbin-Watson statistic was used to test serial autocorrelation; based on the number of observations and regressors in the model we determined an upper and lower bound and tested the null hypothesis of zero autocorrelation in the data [32]. We found first-order autocorrelation in the time-series of the total prescription rate, prescription rate of NVM and of the number of (dispensed) prescription of bupropion and varenicline. These time-series were differenced by subtracting the value of an earlier observation from the value of a later observation in order to control for autocorrelation [25,27]. The regression models were re-checked after time-series were differenced in order to confirm that autocorrelation was accounted for.

\section{RESULTS}

Figure 1 shows the time-series plots of primary care prescriptions of stop-smoking medication and dispensed items in pharmacies in the past decade. It highlights the introduction of the smoking cessation guideline in general practice and the period of the full health insurance coverage of smoking cessation treatment. Both time-series were relatively low in the period 2001-2006, but show a small increase after 2007. Next, both timeseries increased steeply in 2011, especially in the first and last quarters. Thereafter, dispensed prescriptions in pharmacies show a decrease in 2012. Overall, the number of stop-smoking medication prescribed in general practices is lower than dispensed in pharmacies. This can probably be explained by other clinical specialists also prescribing these pharmaceuticals. Further explanations are that GPs sometimes prescribe multiple doses of stop-smoking medications at the same time, and pharmacists sometimes dispense the labelled medication at multiple moments to be able to check for possible side effects [33].

Figure 2 shows the number of primary care prescriptions and dispensed items of NRT, varenicline and bupropion. Visual inspection points out that, between 2001 and 2008, the number of primary care prescriptions of NRT increased in the first quarter of every year, which can be defined as seasonality in the time-series. In this period, the prescription rates of NRT show little change, with a single small increase in 2008. Both timeseries of NRT show a steep increase in 2011, especially in the first and last quarters.

After the introduction of varenicline in December 2006, visual inspection of Fig. 2 shows that both prescriptions and dispensed items of this pharmaceutical

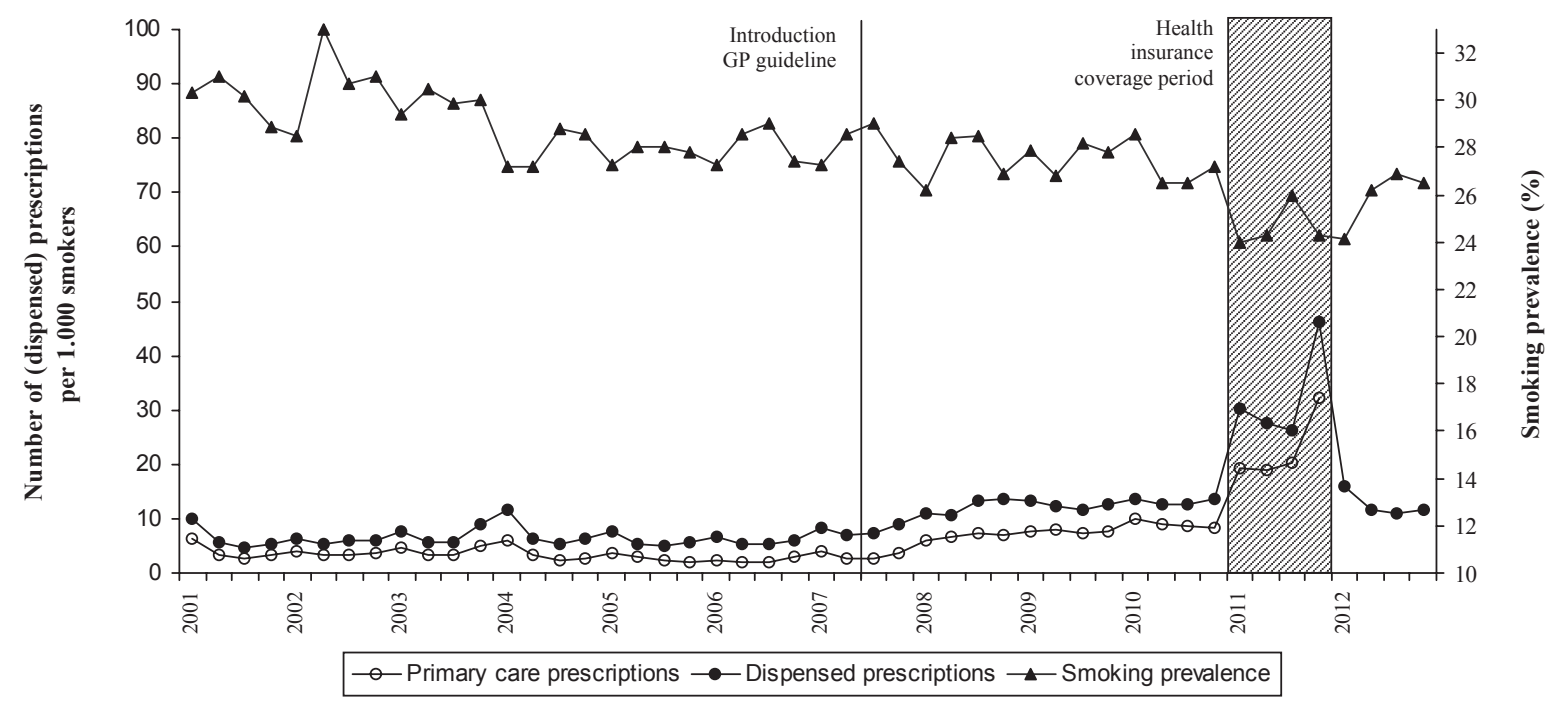

Figure I Smoking prevalence and the number of primary care prescriptions and dispensed prescriptions of stop-smoking medication per 1000 smokers in the period 2001-2012 


\section{Nicotine replacement therapy}

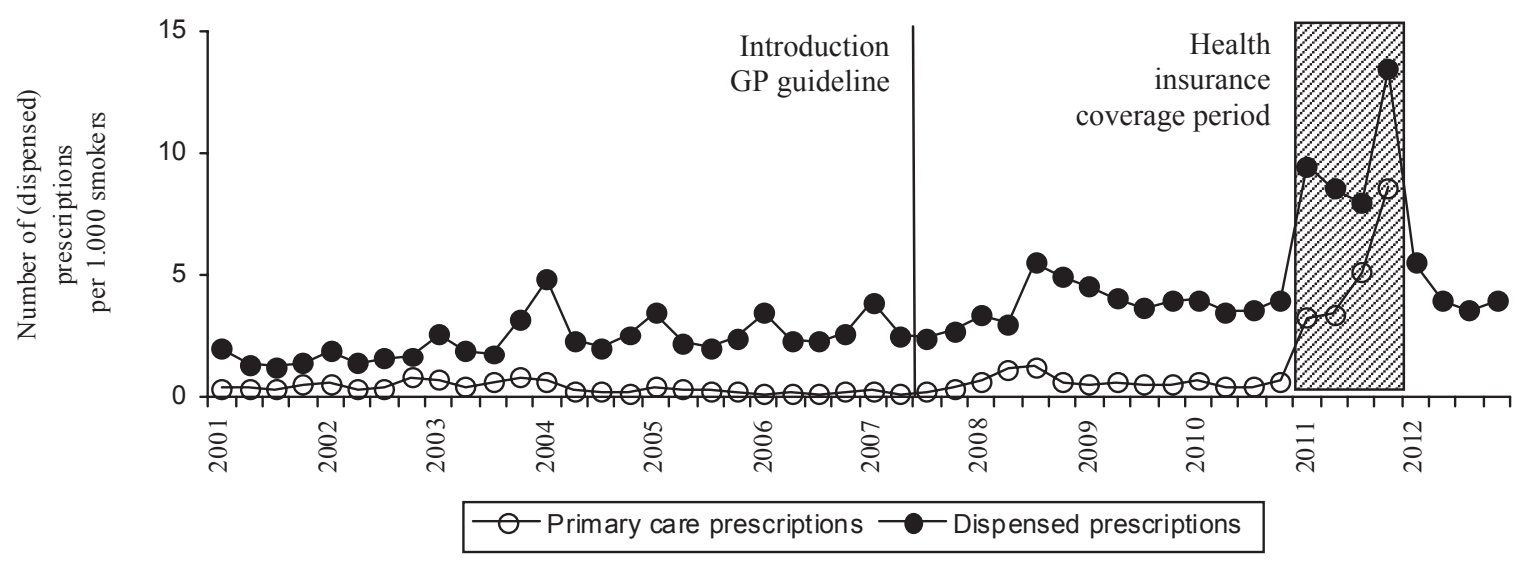

\section{Varenicline}

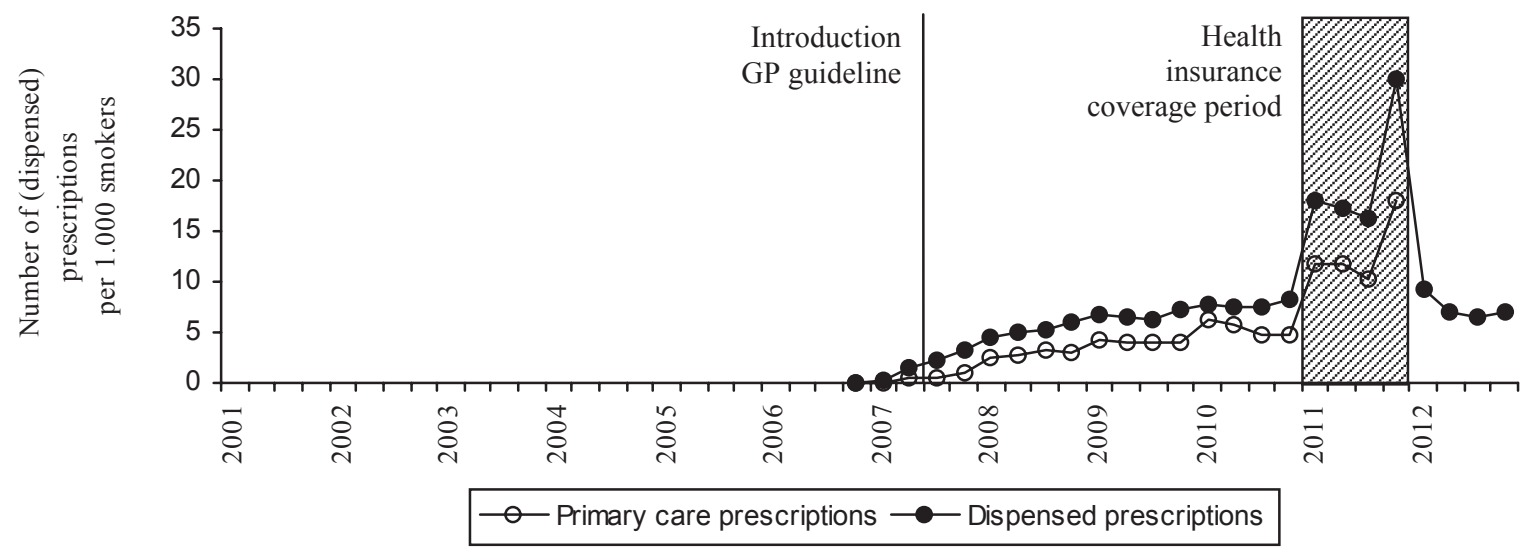

\section{Bupropion}

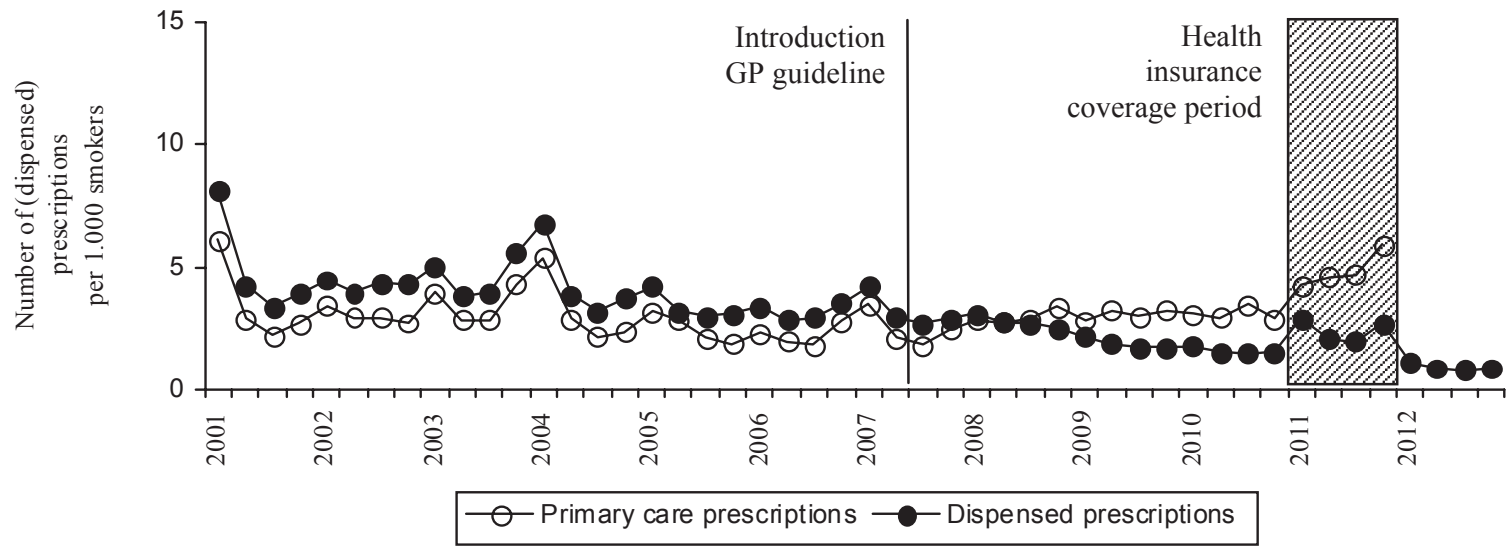

Figure 2 The number of primary care prescriptions and dispensed prescriptions of nicotine replacement therapy, varenicline and bupropion per 1000 smokers in the period 200 I-2012 
increased rapidly, particularly in the first and last quarters of 2011. Next, dispensed items of varenicline show a steep decrease in 2012.

With regard to bupropion, we observed a discrepancy between primary care prescriptions and dispensed items from 2007 (Fig. 2). At that time, bupropion was registered in the Netherlands as an antidepressant in addition to stop-smoking medication [34]. The observed discrepancy can be explained by the fact that the primary care prescriptions in this study represent the total number of prescriptions for both depression and quit smoking and the dispensed items represent only stop-smoking medication. Both prescriptions and dispensed items of bupropion show a single slight increase in 2004. Subsequently, primary care prescriptions of bupropion increase in 2011 and the number of dispensed items show a slight decrease in 2012 .

\section{GP guideline}

When accounting for the effect of the introduction of the health insurance coverage, there was no statistically significant immediate $\left(B_{2}\right)$ and long-term $\left(B_{3}\right)$ effect of the introduction of the GP guideline on the number of primary care prescriptions and dispensed items (Table 1).

\section{Health insurance coverage}

According to the segmented regression analysis, the total number of stop-smoking medication prescribed in general practices and dispensed in pharmacies showed a significant increase in 2011, the year in which smoking cessation treatment was reimbursed (Table 1). In the first quarter of 2011, prescriptions and dispensed items increased by 6.3 per 1000 smokers [95\% confidence interval $(\mathrm{CI})=2.9-9.8 ; P=0.001]$ and 17.3 per 1000 smokers (95\% CI $=12.5-22.0 ; P<0.000)$, respectively (Table 1). This change also occurred in the number of primary care prescriptions and dispensed items of NRT and varenicline (Table 1). Subsequently, a significant decrease in the number of dispensed items of stopsmoking medication was established of 21.6 items per 1000 smokers $(95 \% \mathrm{CI}=26.0$ to $-17.2 ; \mathrm{P}<0.000)$ in the first quarter of 2012, immediately after the abolition of the coverage. This effect also occurred in the number of dispensed items of varenicline and NRT.

\section{Smoking prevalence}

Visual inspection of Fig. 1 shows a steady overall decline in smoking prevalence in the period 2001-2012, with a more prominent decrease in 2004, 2007 and 2011. Thereafter, smoking prevalence shows a marked increase in 2012. Segmented regression analyses confirmed a significant decrease in the first quarter of 2011, immediately after the introduction of the health insurance coverage (Table 1).

\section{DISCUSSION}

In the past decade, the number of primary care prescriptions of stop-smoking medication in general practices and dispensed items in pharmacies increased. We found a significant change in (dispensed) prescriptions following full health insurance coverage of stop-smoking support in the year 2011. Moreover, our data suggest a positive impact of this tobacco control policy on smoking prevalence. We did not find measurable effects of the introduction of a guideline for smoking cessation care in general practice on prescription rates.

\section{Current results compared to previous research}

These results complement other Dutch reports indicating an upward trend in the use of pharmacological aids for smoking cessation in recent years [35]. Nevertheless, relatively few stop-smoking prescriptions are suggested actively by GPs and guidelines for cessation support are often implemented suboptimally in general practice [15,36,37]. Moreover, these guidelines also comprise behavioural cessation support, which we did not address in our study, which may explain why we did not find effects of the introduction of the GP guideline introduction on prescription rates.

Regarding our findings related to the effect of full health insurance coverage on prescription rates and smoking prevalence, the latest research also shows a strong association between this policy and a more than 10-fold increase in telephone counselling for smoking cessation [38]. Moreover, a recent review of 11 randomized controlled trials from four countries found a positive effect of full health insurance coverage on the use of smoking cessation treatment [17].

\section{Strengths and weaknesses}

A strength of our study is that three large nation-wide representative databases were used with regard to prescriptions in general practice, dispensed items in pharmacies and smoking prevalence. With regard to the SFK database, in 2011 an unknown and possibly substantial part of Dutch health insurance companies covered dispensed prescriptions of stop-smoking medications only of specific (online) pharmacies; therefore, the precise number of dispensed items was unknown in this year. This implies that these data might underestimate the actual situation and that the impact of health insurance coverage might be even larger. Another strength of the study is the fact that in the Dutch health-care system 


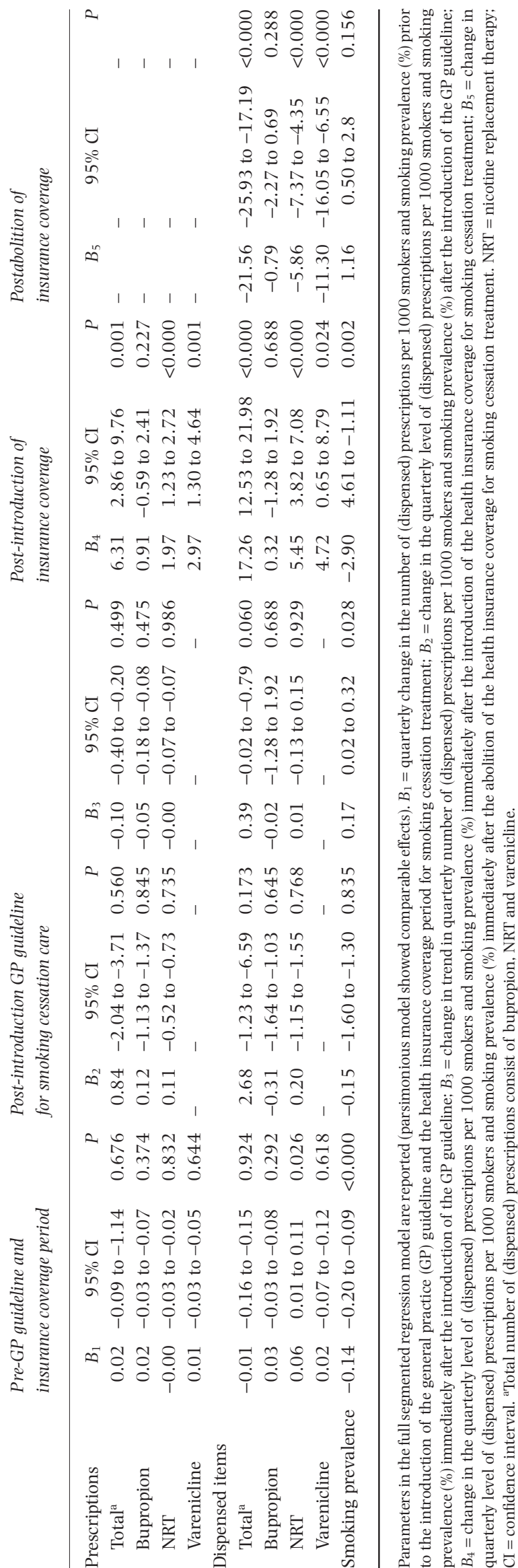


almost all non-institutionalized Dutch citizens are registered with a general practice, which resulted in data with strong external validity.

Regarding the analyses, we assessed the impact of tobacco control interventions with quarterly data points, which enabled us to detect subtle temporary effects in the period prior to or immediately after the interventions. Additionally, we included the most recent available data in order to analyse changes following the abolition of the health insurance coverage.

However, some limitations of the study have to be mentioned. First, it was not possible to differentiate between bupropion prescriptions for treating depression and those used as a quit-smoking aid in general practice. Furthermore, we did not include data regarding NRT distributed over the counter. Because the estimated mean costs of NRT are $€ 2.57$ per day [39], this may have been an incentive for patients to obtain a prescription from the GP during the period that smoking cessation aids were reimbursed. For this reason, it is possible that the reported large increase in the number of (dispensed) prescriptions of NRT in the period 2011-2012 is caused partially by the fact that over-the-counter distribution of these aids are not included into the analyses in the preintervention period.

With regard to the segmented regression analyses, when assessing the impact of an intervention on timeseries the impact of extraneous events on the observed changes in the series must be taken into account [28]. In the past decade, multiple tobacco control policies have been implemented in the Netherlands which might have had an (indirect) effect on the number of prescriptions; for example, tax increases and smoke-free legislation in the work-place (2004) and other public areas (2008). However, in 2011 no other tobacco control measures were introduced in the Netherlands. Although caution is required in assuming causal relations, it seems likely that the increase in (dispensed) prescriptions and decrease in smoking prevalence in 2011 can be attributed to the introduction of health insurance coverage. This assumption is supported by the fact that we visually detected a marked increase in smoking prevalence and statistically confirmed a decrease in dispensed items immediately after the abolition of the coverage.

\section{CONCLUSION AND PRACTICAL IMPLICATIONS}

The results of this study suggest that health insurance coverage for smoking cessation treatment prompt GPs to prescribe evidence-based pharmaceuticals for smoking cessation and have positive effects on smoking prevalence. Therefore, these results are a relevant addition to the existing evidence demonstrating the importance of tobacco control policies in effective tackling of the tobacco epidemic [9-14,28,40,41].

We argue that policy makers and the tobacco control community consider this evidence in developing future tobacco control policy. Given the limitations of our study, we recommend the replication of population-based studies to evaluate further the effectiveness of tobacco control interventions.

\section{Declaration of interests}

None.

\section{References}

1. World Health Organization. Tobacco Fact Sheet. 2011. Available at: http://www.wpro.who.int/mediacentre/ factsheets/fs_201203_tobacco/en/index.html (accessed 24 July 2013). (Archived at http://www.webcitation.org/ 6I9aoQKeN on 16 July 2013).

2. STIVORO. Dutch key figures of smoking in 2011. An overview of recent Dutch data regarding smoking behaviour. The Hague, the Netherlands: STIVORO; 2012.

3. World Health Organization. WHO Global Report: Mortality Attributable to Tobacco. Geneva, Switzerland: World Health Organization; 2012. Available at: http://www.who .int/tobacco/publications/surveillance/rep_mortality _attributable/en/ (accessed 24 July 2013). (Archived at http://www.webcitation.org/6I9b1kgxj on 16 July 2013).

4. Nagelhout G. E. Summary of the World Health Organization Global Report: Mortality Attributable to Tobacco. The Hague, the Netherlands: STIVORO; 2012. Available at: http://stivoro.nl/wp-content/uploads/2012/docs/ rapporten/gezondheidsschade/Samenvatting $\% 20 \mathrm{WHO}$ \%20Report\%20Mortality\%20Attributable\%20to\%20 Tobacco.pdf (accessed 24 July 2013). (Archived at http:// www.webcitation.org/6I9bLZorH on 16 July 2013).

5. Statistics Netherlands. Statistics Causes of Death. 2011. Available at: http://statline.cbs.nl/StatWeb/publication/ ?VW=T\&DM=SLNL\&PA=7233\&HD=130716-1139\&HDR $=\mathrm{T} \& \mathrm{STB}=\mathrm{G} 1, \mathrm{G} 2, \mathrm{G} 3$ (accessed 24 July 2013). (Archived at http://www.webcitation.org/6I9bVrOaV on 16 July 2013).

6. World Health Organization. WHO Report on the Global Tobacco Epidemic. MPOWER: Six Policies to Reverse the Tobacco Epidemic. Geneva, Switzerland: World Health Organization; 2008. Available at: http://www.who.int/ tobacco/mpower/mpower_report_six_policies_2008.pdf (accessed 24 July 2013). (Archived at http://www .webcitation.org/6I9bezOet on 16 July 2013).

7. World Health Organization. Key facts and findings related to the MPOWER package. 2012. Geneva, Switzerland: WHO Tobacco Free Initiatives. 18-7-2012. Available at: http:// www.who.int/tobacco/mpower/facts_findings/en/index .html (accessed 24 July 2013). (Archived at http://www .webcitation.org/6I9bnZuoa on 16 July 2013).

8. Boyle R. G., Solberg L. I., Magnan S., Davidson G., Alesci N. L. Does insurance coverage for drug therapy affect smoking cessation? Health Aff 2002; 21 : 162-8.

9. Kaper J., Wagena E. J., Willemsen M. C., van Schayck C. P. Reimbursement for smoking cessation treatment may double the abstinence rate: results of a randomized trial. Addiction 2005; 100: 1012-20.

10. Kaper J., Wagena E. J., Willemsen M. C., van Schayck C. P. A randomized controlled trial to assess the effects of 
reimbursing the costs of smoking cessation therapy on sustained abstinence. Addiction 2006; 101: 1656-61.

11. Nagelhout G. E., Willemsen M. C., de Vries H. The population impact of smoke-free workplace and hospitality industry legislation on smoking behaviour. Findings from a national population survey. Addiction 2011; 106: 81623.

12. Nagelhout G. E., de Vries H., Fong G. T., Candel M. J., Thrasher J. F., van den Putte B. et al. Pathways of change explaining the effect of smoke-free legislation on smoking cessation in the Netherlands. An application of the international tobacco control conceptual model. Nicotine Tob Res 2012; 12: 1474-82.

13. Nagelhout G. E., Levy D. T., Blackman K., Currie L., Clancy L., Willemsen M. C. The effect of tobacco control policies on smoking prevalence and smoking-attributable deaths. Findings from the Netherlands SimSmoke Tobacco Control Policy Simulation Model. Addiction 2012; 107: 407-16.

14. Nagelhout G. E., de Vries H., Boudreau C., Allwright S., McNeill A., van den Putte B. et al. Comparative impact of smoke-free legislation on smoking cessation in three European countries. Eur J Public Health 2012; 22: 4-9.

15. Wilson A., Sinfield P., Rodgers S., Hammersley V., Coleman T. Drugs to support smoking cessation in UK general practice: are evidence based guidelines being followed? Qual Saf Health Care 2006; 15: 284-8.

16. Pieterse M. E., Seydel E. R., de Vries H., Mudde A. N., Kok G. J. Effectiveness of a minimal contact smoking cessation program for Dutch general practitioners: a randomized controlled trial. Prev Med 2001; 32: 182-90.

17. Reda A. A., Kotz D., Evers S. M., van Schayck C. P. Healthcare financing systems for increasing the use of tobacco dependence treatment. Cochrane Database Syst Rev 2012; (6). Available at: http://onlinelibrary.wiley.com/doi/ 10.1002/14651858.CD004305.pub4/pdf (accessed 11 September 2012). (Archived at http://www.webcitation .org/6I9buvQ2P on 16 July 2013).

18. Stop Smoking Partnership. Guideline Treatment of Tobacco Dependence. Alphen aan den Rijn, the Netherlands: Van Zuiden Communications B.V.; 2004.

19. Chavannes N. H., Kaper J., Frijling B. D., Van der Laan J. R., Jansen P. W. M., Guerrouj S. et al. Dutch college of general practitioners guideline for smoking cessation. Huisarts Wet 2007; 50: 306-14.

20. Wiersma T. J., Chavannes N. H. Addendum Dutch College of general practitioners guideline for smoking cessation: varenicline hereafter suitable for smoking cessation treatment. Huisarts Wet 2011; 54: 156-7.

21. Central Committee on Research involving Human Subjects. The Review System in the Netherlands. 2012. Available at: http://www.ccmo-online.nl/main.asp?pid=1\&taal= (accessed 24 July 2013). (Archived at http://www .webcitation.org/6I9c1erqs on 16 July 2013).

22. Stirbu-Wagner I., Dorsman S., Visscher S., Davids R., Gravenstein J., Abrahamse H. et al. Netherlands Information Network of Primary Care. Facts and Figures on Dutch General Practice. 2010. Utrecht/Nijmegen: NIVEL/IQ. Available at: http://www.LINH.nl (accessed 5 November 2012). (Archived at http://www.webcitation.org/ $619 \mathrm{cBdi} 7 \mathrm{~g}$ on 16 July 2013).

23. Statistics Netherlands. Population core figures. 2013. Available at: http://statline.cbs.nl/StatWeb/publication/?DM $=$ SLNL\&PA $=37296$ ned $\& D 1=0,3,10-13 \& D 2=50-63 \& H D R$ $=\mathrm{G} 1 \& \mathrm{STB}=\mathrm{T} \& V W=\mathrm{T}$ (accessed 24 July 2013). (Archived at http://www.webcitation.org/6I9cHMNv5 on 16 July 2013).

24. STIVORO. Percentage smokers 15 years and older, 20012012. 2013. Available at: http://stivoro.nl/wp-content/ uploads/persberichten/Bijlage $\% 20$ bij\%20persbericht \%20rookcijfer\%202012.pdf (accessed 24 July 2013). (Archived at http://www.webcitation.org/6I9cMCAjX on 16 July 2013).

25. Szatkowski L. C. Can primary care data be used to evaluate the effectiveness of tobacco control policies? Data quality, method development and assessment of the impact of smokefree legislation using data from The Health Improvement Network. Nottingham, UK: University of Nottingham; 2011. Available at: http://etheses.nottingham.ac.uk/ 1902/1/Final_thesis_Lisa_Szatkowski.pdf (accessed 24 July 2013). (Archived at http://www.webcitation.org/ 6ILqEuvp7 on 24 July 2013).

26. Gillings D., Makuc D., Siegel E. Analysis of interrupted time series mortality trends: an example to evaluate regionalized perinatal care. Am J Public Health 1981; 71: 38-46.

27. Wagner A. K., Soumerai S. B., Zhang F., Ross-Degnan D. Segmented regression analysis of interrupted time series studies in medication use research. J Clin Pharm Ther 2002; 27: 299-309.

28. Szatkowski L., Coleman T., McNeill A., Lewis S. The impact of the introduction of smoke-free legislation on prescribing of stop-smoking medications in England. Addiction 2011; 106: $1827-34$.

29. Langley T. E., Huang Y., McNeill A., Coleman T., Szatkowski L., Lewis S. Prescribing of smoking cessation medication in England since the introduction of varenicline. Addiction 2011; 106: 1319-24.

30. Federico B., Mackenbach J. P., Eikemo T. A., Kunst A. E. Impact of the 2005 smoke-free policy in Italy on prevalence, cessation and intensity of smoking in the overall population and by educational group. Addiction 2012; 107: 1677-86.

31. Bajoga U., Lewis S., McNeill A., Szatkowski L. Does the introduction of comprehensive smoke-free legislation lead to a decrease in population smoking prevalence? Addiction 2011; 106: 1346-54.

32. Savin N. E., White K. J. The Durbin-Watson test for serial correlation with extreme sample sizes or many regressors. Econometrica 1977; 45: 1989-96.

33. Dutch Foundation for Pharmaceutical Statistics. Stopsmoking medication dispensed in Dutch pharmacies in the period 2011-2012. 2012.

34. Kidgell A., Mawdsley D., Ferguson S. GlaxoSmithKline receives first European approval for Wellbutrin $\mathrm{XR}^{\circledR}$. Medical News Today. 2007. Available at: http://www.gsk .com/media/press-releases/2007/glaxosmithkline-receives -first-european-approval-for-wellbutrin-xr.html (accessed 24 July 2013). (Archived at http://www.webcitation.org/ 6I9cT60He on 16 July 2013).

35. de Korte D., Nagelhout G. E., Feenstra D., Zeegers T., van der Meer R., Willemsen M. C. Aids for smoking cessation 1992-2008. The Hague, the Netherlands: STIVORO; 2008. Available at: http://stivoro.nl/wp-content/uploads/2012/ docs/rapporten/stoppenmetroken/Themapublicatie $\% 20$ Hulpmiddelen\%20voor\%20Stoppen\%20met\%20Roken \%201992\%202008.pdf (accessed 24 July 2013). (Archived at http://www.webcitation.org/6I9cfp5IK on 16 July 2013).

36. de Korte D., van Schayck O. C. P., van Spiegel P., Kaptein A. A., Sachs A., Rutten-van Mölken M. et al. Supporting 
smoking cessation in healthcare: obstacles in scientific understanding and tobacco addiction management. Health 2010; 2: 1272-9.

37. de Korte D., Nagelhout G. E., Willemsen M. C. Smoking cessation advisement in Dutch general practice: 2001-2009. The Hague, the Netherlands: STIVORO — for a smoke-free future; 2010. Available at: http://stivoro.nl/wp-content/ uploads/themapublicaties/stoppenmetrokenadviezen/ Themapublicatie $\% 20$ Stoppenmetrokenadvisering $\% 20$ door $\% 20$ huisartsen $\% 20 \mathrm{in} \% 20$ Nederland $\% 202001 \% 20$ 2009.pdf (accessed 24 July 2013). (Archived at http:// www.webcitation.org/6I9ckVTDD on 16 July 2013).

38. Willemsen M. C., Segaar D., van Schayck C. P. Population impact of reimbursement for smoking cessation: a natural experiment in the Netherlands. Addiction 2013; 108: $602-4$.

39. Hoogendoorn M., Welsing P., Rutten-van Molken M. P. Costeffectiveness of varenicline compared with bupropion, NRT, and nortriptyline for smoking cessation in the Netherlands. Curr Med Res Opin 2008; 24: 51-61.

40. Bertram M. Y., Lim S. S., Wallace A. L., Vos T. Costs and benefits of smoking cessation aids: making a case for public reimbursement of nicotine replacement therapy in Australia. Tob Control 2007; 16: 255-60.

41. Kaper J., Wagena E. J., van Schayck C. P., Severens J. L. Encouraging smokers to quit: the cost effectiveness of reimbursing the costs of smoking cessation treatment. Pharmacoeconomics 2006; 24: 453-64. 